\title{
Фенотипическая изменчивость жирно-кислотного состава грудного молока
}

\author{
Рудаков О.Б. ${ }^{1}$, Рудакова Л.В. ${ }^{2}$, Букша М.С. ${ }^{2}$ \\ ${ }^{I}$ Воронежский государственный технический университет, Воронеж \\ ${ }^{2}$ Воронежский государственный медицинский университет им. Н.Н. Бурденко, Воронеж
}

Поступила в редакцию 16.01.2019 г.

DOI: https://doi.org/10.17308/sorpchrom.2019.19/643

В статье рассмотрены статистические данные по жирно-кислотному составу грудного молока женщин из разных стран и регионов мира, полученные методом капиллярной газовой хроматографии. Обсуждены биохимические корреляции, наблюдаемые при изменении жирно-кислотного состава в зависимости от региона проживания женщин. Показано, что доля насыщенных жирных кислот (ЖК) относительно постоянна среди большинства стран, за исключением Филиппин и Нигерии, где уровень лауриновой и миристиновой кислот завышен примерно в два раза относительно других стран. Доля мононенасыщенных ЖК различается мало, за исключением пониженного содержания олеиновой кислоты в грудном молоке женщин Филиппин, Нигерии и Туниса. Повышенный уровень эруковой кислоты наблюдается в Китае и Нигерии. Сравнение общего состава ЖК грудного молока из 20 стран и регионов с составом молока женщин из Англии показало, что наиболее близок к нему состав ЖК грудного молока в Австралии, ФРГ и Канаде. Наибольшие различия в составе отмечены между молоком англичанок и молоком женщин Филиппин и Нигерии. Десятикратное различие выявлено в уровне докозагексаеновой кислоты. Он может варьировать от 0.10 до $0.99 \%$. Наибольший уровень этой ЖК характерен для Японии, наименьший - для Туниса. Жирно-кислотный состав грудного молока зависит от диеты кормящих матерей. Характерные для Филиппин и Нигерии показатели указывают на то, что диета кормящих женщин в этих странах не сбалансирована, что отражается на пищевой ценности их грудного молока. Тесные прямые (симбатные) корреляции наблюдаются между содержанием насыщенных короткоцепочных ЖК, тесные обратные корреляции имеют место между содержанием короткоцепочных и длинноцепочных насыщенных ЖК. Между короткоцепочными насыщенными и полиненасыщенными ЖК преобладают отрицательные корреляции. Длинноцепочные насыщенные ЖК, напротив, имеют тенденцию симбатно возрастать при росте содержания полиненасыщенных ЖК. Содержание мононенасыщенных и полиненасыщенных ЖК часто симбатно изменяется при изменении состава молока. Во многих случаях коэффициенты корреляции $R>0.90$. Найденные корреляции полезны при идентификации происхождения молока, при выявлении фальсифицированного женского молока и при оптимизации состава молочных смесей для искусственного вскармливания в разных регионах.

Ключевые слова: грудное молоко, жирно-кислотный состав, фенотипическая изменчивость, капиллярная газовая хроматография

\section{Phenotypic variability fatty acid composition of human milk}

\author{
Rudakov O.B. ${ }^{1}$, Rudakova L.V. ${ }^{2}$, Buksha M.S. $^{2}$ \\ ${ }^{1}$ Voronezh State Technical University, Voronezh \\ ${ }^{2}$ Voronezh State Medical University, Voronezh
}

The article discusses statistical data on the fatty acid composition of human milk of women from different countries and regions of the world, obtained by capillary gas chromatography. Discussed the bio- 
chemical correlations between the region where women live and the fatty acid composition of human milk. It is shown that the proportion of saturated fatty acids (FA) is relatively constant among most countries, with the exception of the Philippines and Nigeria, where the level of lauric and myristic acids is overestimated by about two times compared to other countries. The content of monounsaturated fatty acids slightly differs, except for the low oleic acid content in human milk of women in the Philippines, Nigeria and Tunisia. Erucic acid levels are elevated in China and Nigeria. Comparison of the total composition of the FA of human milk from 20 countries and regions with English human milk showed that the composition of the FA of human milk in Australia, Germany and Canada is closest to it. The greatest differences in composition are found between the milk of Englishwomen and the milk of women in the Philippines and Nigeria. A tenfold difference was found in the level of docosahexaenoic acid. It can vary from $0.10 \%$ to $0.99 \%$. The highest level of this FA is typical for Japan, the lowest - for Tunisia. The fatty acid composition of human milk depends on the diet of nursing mothers. The values characteristic of the Philippines and Nigeria indicate that the diet of nursing women in these countries is not balanced, which affects the nutritional value of their human milk. Close direct (symbate) correlations are observed between the content of saturated short-chain FA, close inverse correlations take place between the content of short-chain and long-chain saturated FA. Negative correlations prevail between short chain saturated and polyunsaturated FA. In contrast, long chain saturated FA tend to increase symbatically with increasing the content of polyunsaturated FA. The content of monounsaturated and polyunsaturated fatty acids often changes symbatically with changes in the composition of milk. The correlation coefficients $\mathrm{R}>0.90$ in most cases. The found correlations are useful in identifying the origin of milk, in identifying adulterated human milk and in optimizing the composition of milk formulas for artificial infant feeding in different regions.

Keywords: human milk, fatty acid composition, phenotypic variability, capillary gas chromatography

\section{Введение}

Грудное молоко - это полидисперсная гетерофазная система, включающая в себя сывороточные белки, казеин, липопротеины, триглицериды, низкомолекулярные азотистые соединения, лактозу, минеральные соли, витамины и большое количество минорных биологически активных компонентов (гормоны, ферменты, цитокины, ростовые факторы, нуклеотиды, иммунные клетки). Объектом изучения в данной работе является жирно-кислотный состав грудного молока. Концентрация жиров в грудном молоке колеблется от 30 до 50 г/дм³. Наибольшую часть жира грудного молока - до 98\% -составляют триглицериды, остальная доля приходится на фосфолипиды, холестерол и свободные жирные кислоты. По составу жирных кислот (ЖК) женское молоко относительно стабильно и содержит около $57 \%$ ненасыщенных жирных кислот и около $42 \%$ насыщенных. Грудное молоко принято за эталонную модель для создания детских молочных смесей $[1,2]$. Его состав, в том числе жирно-кислотный, естественно, считается наиболее сбалансированным для детского питания. Нет никаких оснований считать, что соотношение ЖК в грудном молоке не близко к идеальному и для других возрастных категорий. Конечно, речь идет об усредненном составе зрелого молока. В работах [3,4] рассмотрен критерий пищевой ценности жиров и масел (по составу ЖК), за эталон сравнения в котором взяли содержание наиболее типичных насыщенных и ненасыщенных ЖК, характерных для жира грудного молока.

В связи с неоценимой важностью для детского питания жирно-кислотного состава женского молока, он достаточно хорошо изучен. Приведем лишь некоторые исследования, относящиеся к этой тематике [5-17]. В последнее время отмечена тенденция к росту спроса на продажу грудного молока. Если в России подобная услуга появились сравнительно недавно, в Америке и Европе - это обычная практика в обеспечении полноценного детского питания для состоятельных слоев населения. На продаже грудного молока женщины уже много лет неплохо зарабатывают. Там, где есть дорогой натуральный продукт, возникает проблема его фальсификации, необходимость контроля качества и натуральности. Грудное молоко подменяют козь- 
им молоком, смешивают с молоком домашних животных. В статье [2] показано, чем грудное молоко отличается от козьего и коровьего. Оно имеет более низкую зольность, меньше жира и белков, но более высокое содержание лактозы. Есть различия и в жирно-кислотном составе, как по диапазонам содержания основных, так и минорных жирных кислот.

Уже установлено, что жирно-кислотный состав как коровьего молока, так и растительных масел, варьирует в границах характеристичных диапазонов не статистически случайным образом, а с соблюдением биохимических корреляций $[3,5]$. Если содержание той или иной жирной кислоты (ЖК) в триглицеридах натурального жира или масла, не подвергшихся фракционированию, химическим и термическим воздействиям, падает или возрастает в зависимости от климатических факторов, породы, сорта, питания и т.д., содержание другой ЖК может симбатно возрастать или уменьшаться. Соблюдение диапазонов, в рамках которых содержание ЖК может варьировать, соблюдая при этом природные корреляции, обусловленные генотипическими и фенотипическими факторами, является признаком натуральности данного жира.

Целью настоящей работы было выявить на основании известного массива хроматографических данных о жирно-кислотном составе зрелого грудного молока наличие этих корреляций, установить наиболее характерные соотношения для типичных жирных кислот, проверить, насколько выявленные корреляции могут служить для идентификации натуральности грудного молока.

Методика статистической обработки данных. Парные корреляции и графики построены в табличном процессоре Microsoft Excel 2007. Матрицы корреляций построены в оболочке программы StatSoft Statistica v. 10.0.

\section{Обсуждение результатов}

В табл. 1-3 приведены данные о жирно-кислотном составе грудного молока женщин из разных стран [6-17]. Наиболее корректными и полными, по нашему мнению, являются данные по 9 странам, приведенные в табл. 1 [6]. Исследуемые страны были подобраны для отражения глобальной картины с охватом Азии (Китай, Япония и Филиппины), Австралии, Европы (Великобритания), Северной Америки (Канада, США и Мексика) и Южной Америки (Чили). Общее количество изученных в [6] образцов грудного молока - 440. Для каждой группы (по 44-50 человек) для оценки состава жирных кислот использовали образцы зрелого молока (послеродовой период составлял более 30 дней). Исследование проводили на здоровых, некурящих матерях (14-41 год), обеспечивающих доношенных и здоровых младенцев в возрасте 1-12 месяцев исключительно грудным вскармливанием.

Таблица 1. Усредненный жирно-кислотный состав грудного молока женщин из 9 стран по данным [6]. Первый индекс в обозначении ЖК обозначает количество атомов С, второй - количество двойных связей, третий - номер начального атома С у кратной связи

\begin{tabular}{|c|c|c|c|c|c|c|c|c|c|}
\hline $\begin{array}{l}\text { Жирные } \\
\text { кислоты }\end{array}$ & 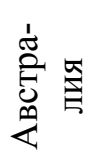 & 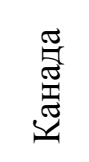 & 莺 & 瓷 & 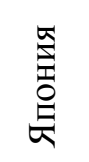 & 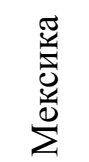 & 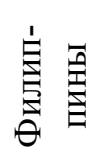 & 焉 & $\overleftrightarrow{\exists}$ \\
\hline 1 & 2 & 3 & 4 & 5 & 6 & 7 & 8 & 9 & 10 \\
\hline $\mathrm{C} 8: 0$ & 0.2 & 0.17 & 0.2 & 0.17 & 0.22 & 0.19 & 0.28 & 0.2 & 0.16 \\
\hline C10:0 & 1.62 & 1.66 & 1.87 & 1.67 & 2 & 1.46 & 2.35 & 1.84 & 1.5 \\
\hline
\end{tabular}




\begin{tabular}{|c|c|c|c|c|c|c|c|c|c|}
\hline 1 & 2 & 3 & 4 & 5 & 6 & 7 & 8 & 9 & 10 \\
\hline C12:0 & 5.49 & 5.25 & 6.15 & 4.24 & 5.86 & 4.97 & 13.82 & 4.99 & 4.4 \\
\hline C13:0 & 0.03 & 0.04 & 0.04 & 0.01 & 0.03 & 0.03 & 0.03 & 0.05 & 0.02 \\
\hline C14:0 & 6.28 & 5.84 & 6.8 & 3.61 & 6.11 & 5.57 & 12.12 & 5.87 & 4.91 \\
\hline C15:0 & 0.39 & 0.33 & 0.3 & 0.12 & 0.29 & 0.32 & 0.21 & 0.36 & 0.29 \\
\hline C16:0 & 22.26 & 18.67 & 18.79 & 18.62 & 20.2 & 19.91 & 23.02 & 22.59 & 19.26 \\
\hline $\mathrm{C} 17: 0$ & 0.41 & 0.32 & 0.35 & 0.22 & 0.32 & 0.33 & 0.24 & 0.29 & 0.32 \\
\hline C18:0 & 6.77 & 5.83 & 5.77 & 6.13 & 6.14 & 6.07 & 4.75 & 6.25 & 6.21 \\
\hline C20:0 & 0.2 & 0.2 & 0.21 & 0.2 & 0.2 & 0.18 & 0.13 & 0.2 & 0.19 \\
\hline C22:0 & 0.08 & 0.1 & 0.09 & 0.09 & 0.09 & 0.08 & 0.06 & 0.08 & 0.09 \\
\hline C24:0 & 0.06 & 0.06 & 0.08 & 0.05 & 0.05 & 0.05 & 0.05 & 0.06 & 0.06 \\
\hline C14:1n-5 & 0.31 & 0.25 & 0.18 & 0.06 & 0.2 & 0.2 & 0.5 & 0.28 & 0.22 \\
\hline C16:1n-9 & 0.42 & 0.23 & 0.4 & 0.49 & 0.36 & 0.35 & 0.08 & 0.44 & 0.44 \\
\hline C16:1n-7 & 2.97 & 2.79 & 2.7 & 1.88 & 2.56 & 2.64 & 4.59 & 2.85 & 2.64 \\
\hline C16:1n-5 & 0.12 & 0.1 & 0.11 & 0.03 & 0.09 & 0.09 & 0.2 & 0.11 & 0.1 \\
\hline C16:1n-3 & 0.19 & 0.12 & 0.06 & 0.05 & 0.12 & 0.13 & 0.06 & 0.14 & 0.11 \\
\hline C17:1n-7 & 0.34 & 0.28 & 0.27 & 0.17 & 0.25 & 0.24 & 0.23 & 0.27 & 0.26 \\
\hline C18:1n-9 & 32.23 & 35.18 & 26.19 & 36.49 & 31.43 & 30.79 & 21.85 & 33.28 & 32.77 \\
\hline C18:1n-7 & 2.37 & 2.85 & 2.67 & 2.13 & 2.32 & 2.72 & 2.25 & 2.5 & 2.88 \\
\hline C18:1n-5 & 0.35 & 0.26 & 0.21 & 0.08 & 0.18 & 0.23 & 0.14 & 0.18 & 0.3 \\
\hline C20:1n-11 & 0.23 & 0.2 & 0.23 & 0.06 & 0.27 & 0.22 & 0.08 & 0.19 & 0.21 \\
\hline C20:1n-9 & 0.38 & 0.52 & 0.55 & 1.25 & 0.52 & 0.42 & 0.28 & 0.44 & 0.39 \\
\hline C22:1n-9 & 0.08 & 0.11 & 0.14 & 1.21 & 0.13 & 0.08 & 0.07 & 0.1 & 0.08 \\
\hline C14:2n-6 & 0.15 & 0.1 & 0.1 & 0.04 & 0.1 & 0.11 & 0.04 & 0.13 & 0.09 \\
\hline C16:2n-6 & 0.29 & 0.22 & 0.24 & 0.1 & 0.2 & 0.23 & 0.09 & 0.22 & 0.2 \\
\hline C18:2n-6 & 10.66 & 11.48 & 17.75 & 14.88 & 12.66 & 16.05 & 7.9 & 10.45 & 14.78 \\
\hline C18:3n-6 & 0.17 & 0.16 & 0.15 & 0.15 & 0.13 & 0.15 & 0.1 & 0.17 & 0.17 \\
\hline $\mathrm{C} 20: 2 \mathrm{n}-6$ & 0.2 & 0.21 & 0.54 & 0.39 & 0.25 & 0.34 & 0.23 & 0.22 & 0.27 \\
\hline C20:3n-6 & 0.31 & 0.27 & 0.44 & 0.28 & 0.25 & 0.33 & 0.31 & 0.33 & 0.35 \\
\hline C20:4n-6 & 0.38 & 0.37 & 0.42 & 0.49 & 0.4 & 0.42 & 0.39 & 0.36 & 0.45 \\
\hline $\mathrm{C} 22: 4 n-6$ & 0.09 & 0.04 & 0.04 & 0.11 & 0.08 & 0.11 & 0.11 & 0.08 & 0.11 \\
\hline $\mathrm{C} 22: 5 n-6$ & 0.04 & 0.04 & 0.09 & 0.06 & 0.05 & 0.05 & 0.08 & 0.03 & 0.06 \\
\hline C18:3n-3 & 0.9 & 1.22 & 1.14 & 2.02 & 1.33 & 1.05 & 0.43 & 1.22 & 1.05 \\
\hline C18:4n-3 & 0.01 & 0.02 & 0.01 & 0.05 & 0.06 & 0.04 & 0.03 & 0.03 & 0.01 \\
\hline C20:3n-3 & 0.04 & 0.04 & 0.07 & 0.13 & 0.05 & 0.04 & 0.04 & 0.05 & 0.04 \\
\hline C20:4n-3 & 0.08 & 0.08 & 0.09 & 0.1 & 0.12 & 0.07 & 0.09 & 0.11 & 0.08 \\
\hline C20:5n-3 & 0.1 & 0.08 & 0.09 & 0.07 & 0.26 & 0.07 & 0.15 & 0.11 & 0.07 \\
\hline $\mathrm{C} 22: 5 \mathrm{n}-3$ & 0.18 & 0.16 & 0.22 & 0.18 & 0.29 & 0.16 & 0.23 & 0.18 & 0.14 \\
\hline C22:6n-3 & 0.23 & 0.17 & 0.43 & 0.35 & 0.99 & 0.26 & 0.74 & 0.24 & 0.17 \\
\hline
\end{tabular}

Таблица 2. Усредненный жирно-кислотный состав зрелого грудного молока женщин из 6 стран по данным [11,15,17]

\begin{tabular}{|c|c|c|c|c|c|c|c|}
\hline $\begin{array}{c}\text { Жирные } \\
\text { кислоты }\end{array}$ & $\begin{array}{c}\text { Ниге- } \\
\text { рия[15] }\end{array}$ & Турция[15] & Тунис[15] & $\begin{array}{c}\text { Чунцин, } \\
\text { Китай } \\
{[11]}\end{array}$ & $\begin{array}{c}\text { Гонконг, } \\
\text { Китай } \\
{[11]}\end{array}$ & $\begin{array}{c}\text { Канада } \\
{[11]}\end{array}$ & $\begin{array}{c}\text { ФГ } \\
{[17]}\end{array}$ \\
\hline 1 & 2 & 3 & 4 & 5 & 6 & 7 & 8 \\
\hline $\mathrm{C} 8: 0$ & - & 0.07 & 0.59 & - & - & - & - \\
\hline $\mathrm{C} 10: 0$ & 0.54 & 1.02 & 3.82 & 0.81 & 0.53 & 1.39 & 0.71 \\
\hline $\mathrm{C} 12: 0$ & 8.34 & 5.9 & 8.29 & 4.45 & 4.23 & 5.68 & 4.41 \\
\hline $\mathrm{C} 13: 0$ & 0.15 & - & - & - & - & - & 0.05 \\
\hline $\mathrm{C} 14: 0$ & 9.57 & 6.46 & 8.44 & 4.22 & 5.5 & 6.1 & 6.73 \\
\hline $\mathrm{C} 15: 0$ & 0.54 & 0.28 & 0.42 & 0.13 & 0.31 & 0.37 & 0.46 \\
\hline $\mathrm{C} 16: 0$ & 23.35 & 20.9 & 28.84 & 22.79 & 21.29 & 18.3 & 21.18 \\
\hline
\end{tabular}




\begin{tabular}{|c|c|c|c|c|c|c|c|}
\hline 1 & 2 & 3 & 4 & 5 & 6 & 7 & 8 \\
\hline $\mathrm{C} 17: 0$ & 0.44 & 0.18 & 0.39 & 0.25 & 0.32 & 0.32 & 0 \\
\hline $\mathrm{C} 18: 0$ & 10.15 & 5.66 & 4.29 & 7.74 & 5.86 & 6.15 & 8.15 \\
\hline $\mathrm{C} 20: 0$ & 0.42 & 0.23 & 0.06 & 0.2 & 0.2 & 0.15 & 0.22 \\
\hline $\mathrm{C} 22: 0$ & 0.41 & 0.01 & - & - & - & - & 0.09 \\
\hline $\mathrm{C} 24: 0$ & 0.39 & 0.01 & - & - & - & - & 0.03 \\
\hline $\mathrm{C} 14: 1 \mathrm{n}-5$ & 0.08 & 0.14 & 0.46 & 0.01 & 0.01 & 0.28 & 0.29 \\
\hline $\mathrm{C} 16: 1 \mathrm{n}-9$ & - & - & 0.41 & 0.59 & 0.56 & 0.41 & - \\
\hline $\mathrm{C} 16: 1 \mathrm{n}-7$ & 0.91 & 1.51 & 2.25 & 2.46 & 2.23 & 2.27 & 2.68 \\
\hline $\mathrm{C} 17: 1 \mathrm{n}-7$ & 0.13 & 0.01 & 0.14 & 0.19 & 0.22 & 0.21 & 0.32 \\
\hline $\mathrm{C} 18: 1 \mathrm{n}-9$ & 18.52 & 27.31 & 27.12 & 37.15 & 34.4 & 30.65 & 34.31 \\
\hline $\mathrm{C} 18: 1 \mathrm{n}-7$ & 0.95 & - & - & - & - & - & - \\
\hline $\mathrm{C} 20: 1 \mathrm{n}-11$ & - & 0.27 & - & - & - & - & - \\
\hline $\mathrm{C} 20: 1 \mathrm{n}-9$ & 0.34 & - & - & 0.97 & 0.79 & 0.39 & 0.52 \\
\hline $\mathrm{C} 22: 1 \mathrm{n}-9$ & 0.75 & 0.01 & - & - & - & - & 0.08 \\
\hline $\mathrm{C} 18: 2 \mathrm{n}-6$ & 11.06 & 24.31 & 10.89 & 10.44 & 15.8 & 10.47 & 10.76 \\
\hline $\mathrm{C} 18: 3 \mathrm{n}-6$ & 0.12 & 0.18 & 0.28 & 0.11 & 0.15 & 0.08 & 0.14 \\
\hline $\mathrm{C} 20: 2 \mathrm{n}-6$ & 0.26 & - & 0.04 & 0.44 & 0.68 & 0.17 & 0.34 \\
\hline $\mathrm{C} 20: 3 \mathrm{n}-6$ & 0.49 & - & 0.37 & 0.37 & 0.41 & 0.26 & 0.26 \\
\hline $\mathrm{C} 20: 4 \mathrm{n}-6$ & 0.82 & - & 0.12 & 0.76 & 0.61 & 0.35 & 0.36 \\
\hline $\mathrm{C} 22: 4 \mathrm{n}-6$ & 0.09 & - & - & 0.17 & 0.23 & 0.04 & 0.08 \\
\hline $\mathrm{C} 22: 5 \mathrm{n}-6$ & 0.09 & - & - & 0.1 & 0.09 & 0.01 & 0.03 \\
\hline $\mathrm{C} 18: 3 \mathrm{n}-3$ & 1.41 & 0.59 & - & 1.17 & 1.24 & 1.16 & 0.82 \\
\hline $\mathrm{C} 18: 4 \mathrm{nn}-3$ & 0.09 & 0.23 & - & - & - & - & - \\
\hline $\mathrm{C} 20: 3 \mathrm{n}-3$ & 0.27 & - & - & - & - & - & 0.06 \\
\hline $\mathrm{C} 20: 4 \mathrm{nn}-3$ & 0.14 & 0.46 & - & - & - & - & - \\
\hline $\mathrm{C} 20: 5 \mathrm{n}-3$ & 0.48 & 0.01 & - & 0.04 & 0.08 & 0.05 & 0.04 \\
\hline $\mathrm{C} 22: 5 \mathrm{n}-3$ & 0.39 & - & - & 0.22 & 0.23 & 0.08 & 0.17 \\
\hline $\mathrm{C} 22: 6 \mathrm{n}-3$ & 0.93 & 0.15 & 0.1 & 0.54 & 0.56 & 0.14 & 0.22 \\
\hline
\end{tabular}

Таблица 3. Усредненный жирно-кислотный состав зрелого грудного молока женщин из 5 стран по данным [16]

\begin{tabular}{|c|c|c|c|c|c|}
\hline Жирные кислоты & Израиль & Голландия & Франция & Испания & Судан \\
\hline 1 & 2 & 3 & 4 & 5 & 6 \\
\hline $\mathrm{C} 8: 0$ & - & 0.08 & 0.19 & 0.13 & - \\
\hline $\mathrm{C} 10: 0$ & - & 0.81 & 1.23 & 1.32 & 0.59 \\
\hline $\mathrm{C} 11: 0$ & - & - & 0.02 & & 0.01 \\
\hline $\mathrm{C} 12: 0$ & - & 5.14 & 5.15 & 5.9 & 6.66 \\
\hline $\mathrm{C} 13: 0$ & - & - & 0.04 & 1.13 & 0.04 \\
\hline $\mathrm{C} 14: 0$ & 15.15 & 8.00 & 6.9 & 6.25 & 10.13 \\
\hline $\mathrm{C} 15: 0$ & - & 0.22 & 0.42 & 0.3 & - \\
\hline $\mathrm{C} 16: 0$ & 20.14 & 17.85 & 21.62 & 19.45 & 22.1 \\
\hline $\mathrm{C} 17: 0$ & - & 0.21 & 0.36 & 0.36 & 0.5 \\
\hline $\mathrm{C} 18: 0$ & 5.53 & 5.32 & 7.64 & 6.85 & 5.21 \\
\hline $\mathrm{C} 20: 0$ & - & 0.22 & 0.22 & 0.23 & 0.14 \\
\hline $\mathrm{C} 24: 0$ & 0.24 & - & 0.06 & - & 0.07 \\
\hline $\mathrm{C} 14: 1$ & - & - & - & - & 0.06 \\
\hline $\mathrm{C} 16: 1$ & - & 0.11 & 0.35 & 0.21 & 0.41 \\
\hline $\mathrm{C} 18: 1$ & 2.63 & 1.44 & 2.15 & 2.07 & 2.47 \\
\hline $\mathrm{C} 20: 1$ & 30.07 & 32.25 & 32.15 & 38.39 & 29.05 \\
\hline $\mathrm{C} 18: 2$ & 0.47 & 0.42 & 0.78 & 0.51 & 0.47 \\
\hline $\mathrm{C} 18: 3$ & 20.02 & 22.42 & 14.67 & 12.02 & 18.28 \\
\hline & 1.57 & 1.10 & 0.70 & 0.78 & 0.67 \\
\hline
\end{tabular}




\begin{tabular}{|c|c|c|c|c|c|}
\hline 1 & 2 & 3 & 4 & 5 & 6 \\
\hline $\mathrm{C} 20: 2$ & - & 0.45 & $0.52-$ & 0.41 & 0.39 \\
\hline $\mathrm{C} 20: 3$ & - & 0.38 & 0.04 & 0.5 & 0.44 \\
\hline $\mathrm{C} 20: 4$ & 0.58 & 0.41 & 0.08 & 0.5 & 0.5 \\
\hline $\mathrm{C} 20: 5$ & - & 0.05 & - & 0.14 & 0.01 \\
\hline $\mathrm{C} 22: 2$ & - & 0.12 & - & - & 0.08 \\
\hline $\mathrm{C} 22: 4$ & - & 0.08 & - & 0.17 & 0.15 \\
\hline $\mathrm{C} 22: 5$ & - & 0.05 & 0.16 & 0.12 & 0.11 \\
\hline $\mathrm{C} 22: 6$ & 0.37 & 0.23 & 0.32 & 0.34 & 0.07 \\
\hline
\end{tabular}

Что касается данных, опубликованных в работах [7-17] (табл. 2,3), обращает на себя внимание отсутствие информации о содержании ряда минорных ЖК (содержание $\leq 0.2 \%$ ). В этих работах нередко нет разделения на геометрические и позиционные изомеры, высока вероятность недостоверной идентификации некоторых минорных ЖК. В работах указывается, что определенное количество (до 4\%) ЖК не идентифицировано. Такая ситуация связана с техническими сложностями хроматографического разделения ЖК. Жиры при пробоподготовке, как известно, переэтерифицируют метанолом в летучие сложные эфиры. Времена удерживания сложных эфиров таких ЖК могут быть слишком близкими, что не позволяет разделить пики индивидуальных компонентов, если при определении жирно-кислотного состава методом ГЖХ используются капиллярные колонки длиной $\leq 30$ м, что, как раз имело место в ряде исследований, приведенных в цитируемой литературе. Наиболее надежную идентификацию ЖК молочного жира можно провести с использованием капиллярных колонок длиной 50-100 м, либо с применением двухмерной газовой хроматографии с масс-спектрометрическим детектором (ГХ-ГХ-МС). Возможны потери минорных кислот в процессе переэтерификации, частичная изомеризация. Но такие недочеты не вносят существенных погрешностей в определение ЖК с высокими концентрациями и не мешают проверке их соотношений.

Анализ данных [6,7-17] показал, что доля насыщенных жирных кислот относительно постоянна среди большинства стран, за исключением Филиппин и Нигерии, где уровень лауриновой и миристиновой кислот был превышен примерно в два раза относительно других стран. Доля мононенасыщенных жирных кислот различается мало, за исключением пониженного содержания олеиновой кислоты (C18:1) на Филиппинах, в Нигерии и Тунисе и повышенного показателя эруковой кислоты (C22:1) в Китае и Нигерии (табл. 4). В этой таблице приведены данные для 21 региона из различных источников, охватывающих более 1000 результатов исследований. В качестве шкалы сравнения были выбраны данные об усредненном составе грудного молока женщин Англии. Оказалось, что по суммарному содержанию ему наиболее близок состав грудного молока в Австралии, ФРГ, Канаде, Японии и отдельных районов Китая ( $\mathrm{R} \geq 0.993)$. Наибольшие различия в составе отмечены между молоком англичанок и молоком женщин Израиля, Турции, Филиппин и Нигерии $(\mathrm{R} \leq 0.926)$. B сравнении с Англией более чем в половине стран и регионов завышенным оказалось содержание линолевой кислоты (С18:2).

Из минорных полиненасыщенных кислот отмечается различный уровень некоторых полиненасыщенных жирных кислот. Так, уровень докозагексаеновой кислоты (C22:6n-3) варьируется между 0.10 и 0.99\% - наибольший показатель в Японии и Нигерии, наименьший - в Судане и Тунисе (табл. 5). Можно сделать ожидаемый вывод, что жирно-кислотный состав грудного молока сильно зависит от диеты. В Японии, например, принимают в пищу много морепродуктов, богатых полиненасыщенными кислотами, отсюда в молоке высокий уровень докозагексаеновой кислоты. Высокий уровень линоленовой кислоты в молоке для таких стран как Мекси- 
ка и Чили связан с тем, что в рационе питания в этих регионах преобладает кукуруза. Образцы молока из Филиппин были получены от женщин с низким экономическим статусом. Высокий уровень содержания лауриновой и миристиновой кислот в молоке свидетельствует о том, что рацион этих женщин связан с высоким содержанием углеводов и низким содержанием жира. Аналогичный вывод можно сделать о рационе питания нигерийских женщин. Крайние значения, характерные для Филиппин и Нигерии указывают на то, что диета кормящих женщин в этих странах не вполне сбалансирована, что отражается на пищевой ценности их грудного молока. На рис. 1 и 2 в качестве примера показано как соотносятся между собой составы ЖК грудного молока женщин Англии, Австралии и Нигерии. На графиках отложено процентное содержание всех жирных кислот, входящих в состав грудного молока, т.е., каждая точка на них означает процентное содержание той или иной ЖК в сравниваемых образцах грудного молока. Чем ближе процентное содержание сравниваемых образцов, тем выше корреляция.

Таблица 4. Коэффициенты корреляции между общим составом ЖК грудного молока женщин из разных регионов и наиболее заметные положительные или отрицательные отклонения содержания отдельных ЖК от жирно-кислотного состава грудного молока английских женщин по данным [6,11,15-17]

\begin{tabular}{|c|c|ccc|}
\hline Регион & $\begin{array}{c}\text { Корреляция, } \\
R\end{array}$ & Наиболее заметные отклонения в содержании ЖК \\
\hline Англия[6] & 1.000 & & & \\
Австралия[6] & 0.999 & & & \\
ФРГ[17] & 0.997 & & & \\
Япония[6] & 0.996 & & & \\
Чунцин[11], & 0.996 & & & \\
Канада[6] & 0.996 & & & \\
Канада[11] & 0.993 & & & \\
Франция[16] & 0.992 & $\mathrm{C} 18: 2 \uparrow *$ & & \\
США[6] & 0.990 & $\mathrm{C} 18: 2 \uparrow$ & & \\
Испания[16] & 0.990 & $\mathrm{C} 18: 2 \uparrow$ & & \\
Гонконг[11] & 0.989 & $\mathrm{C} 18: 2 \uparrow$ & & \\
Мексика[6] & 0.986 & $\mathrm{C} 18: 2 \uparrow$ & & \\
Китай[6] & 0.984 & $\mathrm{C} 18: 2 \uparrow$ & $\mathrm{C} 16: 0 \downarrow$ & \\
Чили[6] & 0.968 & $\mathrm{C} 18: 2 \uparrow$ & & \\
Судан[16] & 0.965 & $\mathrm{C} 18: 2 \uparrow$ & $\mathrm{C} 12: 0 \uparrow$ & \\
Тунис[15] & 0.964 & $\mathrm{C} 16: 0 \uparrow$ & $\mathrm{C} 18: 1 \downarrow$ & \\
Голландия[16] & 0.942 & $\mathrm{C} 18: 2 \uparrow$ & $\mathrm{C} 16: 0 \downarrow$ & \\
Израиль[16] & 0.926 & $\mathrm{C} 18: 2 \uparrow$ & $\mathrm{C} 14: 0 \uparrow$ & \\
Турция[15] & 0.921 & $\mathrm{C} 18: 2 \uparrow$ & & \\
Филиппины[6] & 0.917 & $\mathrm{C} 12: 0 \uparrow$ & $\mathrm{C} 14: 0 \uparrow$ & $\mathrm{C} 18: 1 \downarrow$ \\
Нигерия[15] & 0.917 & $\mathrm{C} 12: 0 \uparrow$ & $\mathrm{C} 14: 0 \uparrow$ & $\mathrm{C} 18: 0 \uparrow$ \\
\hline
\end{tabular}

* Стрелками $\uparrow$ обозначены существенные положительные, а стрелками $\downarrow$ - отрицательные отклонения от среднестатистических значений, характерных для грудного молока женщин Англии

Таблица. 5. Усредненный уровень докозагексаеновой кислоты (C22:6n-3) в женском молоке женщин разных регионов по данным [6,11,15-17], \%

\begin{tabular}{|c|c|c|c|}
\hline Япония & 0.99 & Англия & 0.24 \\
\hline Нигерия & 0.93 & Австралия & 0.23 \\
\hline Филиппины & 0.74 & Голландия & 0.23 \\
\hline Китай & 0.46 & ФРГ & 0.22 \\
\hline Чили & 0.43 & США & 0.17 \\
\hline
\end{tabular}




\begin{tabular}{|c|c|c|c|}
\hline Израиль & 0.37 & Канада & 0.16 \\
\hline Испания & 0.34 & Турция & 0.15 \\
\hline Франция & 0.32 & Судан & 0.11 \\
\hline Мексика & 0.26 & Тунис & 0.10 \\
\hline
\end{tabular}

Важным фактором, на который не было обращено внимание в цитированных работах [6,7-17], является то, что состав ЖК в натуральном женском молоке в рамках характерных диапазонов изменяется не произвольно, а с соблюдением корреляций, обусловленных фенотипической изменчивостью и биохимическими закономерностями. В табл. 6-11 приведены матрицы коэффициентов корреляции $R$ между массовой долей $W(\%)$ насыщенных, моно- и полиненасыщенных ЖК в грудном молоке $(\mathrm{n}=440, \mathrm{P}=0.95)$ по данным [6]. Как видно из этих таблиц, содержание некоторых жирных кислот грудного молока изменяется не случайным образом, существует значительное количество значимых прямых и обратных корреляций $(R>0.60$ и $R<-0.60$ соответственно). Так, существуют достаточно тесные положительные корреляции между содержанием насыщенных короткоцепочных ЖК (C10:0, C12:0, C14:0, $\mathrm{C} 16: 0)$, их доля возрастает при изменении состава молочного жира симбатно, тесные обратные корреляции имеют место между содержанием короткоцепочных и длинноцепочных насыщенных ЖК (C18:0, С20:0 и С22:0), если содержание одних растет, доля других в жире грудного молока падает. Примечательно, что доли ЖК с нечетным числом атомов (C13:0 и С15:0, С15:0 и C17:0) имеют значимые парные корреляции только между собой. На рис. 3 и 4 приведены частные примеры таких корреляций.

Таблица. 6. Матрица коэффициентов парной корреляции $R$ между $W(\%)$ насыщенных ЖК в грудном молоке $(n=440, P=0.95)$

\begin{tabular}{|c|c|c|c|c|c|c|c|c|c|c|c|}
\hline ЖК & $\mathrm{C} 8: 0$ & $\mathrm{C} 10: 0$ & $\mathrm{C} 12: 0$ & $\mathrm{C} 13: 0$ & $\mathrm{C} 14: 0$ & $\mathrm{C} 15: 0$ & $\mathrm{C} 16: 0$ & $\mathrm{C} 17: 0$ & $\mathrm{C} 18: 0$ & $\mathrm{C} 20: 0$ & $\mathrm{C} 22: 0$ \\
\hline $\mathrm{C} 8: 0$ & 1 & $\mathbf{0 . 8 9 *}$ & $\mathbf{0 . 9 1}$ & 0.21 & $\mathbf{0 . 9 2}$ & -0.12 & $\mathbf{0 . 7 1}$ & -0.22 & $-0.67 *$ & -0.74 & -0.82 \\
\hline $\mathrm{C} 10: 0$ & & 1 & $\mathbf{0 . 8 4}$ & 0.23 & $\mathbf{0 . 8 2}$ & -0.29 & 0.51 & -0.41 & -0.73 & -0.57 & -0.57 \\
\hline $\mathrm{C} 12: 0$ & & & 1 & 0.09 & $\mathbf{0 . 9 7}$ & -0.26 & 0.57 & -0.34 & -0.85 & -0.88 & -0.79 \\
\hline $\mathrm{C} 13: 0$ & & & & 1 & 0.27 & $\mathbf{0 . 7 0}$ & 0.35 & 0.34 & -0.07 & 0.13 & -0.04 \\
\hline $\mathrm{C} 14: 0$ & & & & & 1 & -0.05 & $\mathbf{0 . 6 3}$ & -0.16 & -0.79 & -0.82 & -0.78 \\
\hline $\mathrm{C} 15: 0$ & & & & & & 1 & 0.29 & $\mathbf{0 . 8 4}$ & 0.47 & 0.33 & 0.11 \\
\hline $\mathrm{C} 16: 0$ & & & & & & & 1 & 0.02 & -0.15 & -0.53 & -0.83 \\
\hline $\mathrm{C} 17: 0$ & & & & & & & & 1 & 0.57 & 0.45 & 0.25 \\
\hline $\mathrm{C} 18: 0$ & & & & & & & & & 1 & $\mathbf{0 . 7 7}$ & 0.50 \\
\hline $\mathrm{C} 20: 0$ & & & & & & & & & & 1 & $\mathbf{0 . 8 3}$ \\
\hline $\mathrm{C} 22: 0$ & & & & & & & & & & & 1 \\
\hline
\end{tabular}

* Жирным шрифтом выделены прямые значимые корреляции, а курсивом - обратные.

Таблица 7. Матрица коэффициентов парной корреляции $R$ между $W(\%)$ насыщенных ЖК и мононенасыщенных ЖК в грудном молоке $(n=440, P=0.95)$

\begin{tabular}{|c|c|c|c|c|c|c|c|c|c|c|c|c|}
\hline ЖК & $\begin{array}{l}\stackrel{n}{\leftrightarrows} \\
\stackrel{\Xi}{\dot{\Xi}} \\
\ddot{U}\end{array}$ & $\begin{array}{l}\stackrel{a}{\leftrightarrows} \\
\ddot{b} \\
\ddot{U}\end{array}$ & $\begin{array}{l}\vec{\Xi} \\
\ddot{\Xi} \\
\dot{U}\end{array}$ & $\begin{array}{l}n \\
\stackrel{n}{\Xi} \\
\ddot{b} \\
u\end{array}$ & $\begin{array}{l}\stackrel{n}{\leftrightarrows} \\
\ddot{\sigma} \\
\ddot{U}\end{array}$ & $\begin{array}{r}\stackrel{\Xi}{\Xi} \\
\ddot{\Xi}\end{array}$ & $\begin{array}{l}\hat{i} \\
\ddot{\Xi} \\
\ddot{\infty} \\
\vec{u}\end{array}$ & $\begin{array}{c}\bar{I} \\
\ddot{\infty} \\
\dot{0}\end{array}$ & $\begin{array}{l}\stackrel{n}{\Xi} \\
\ddot{\infty} \\
\dot{0}\end{array}$ & 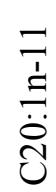 & $\begin{array}{l}\stackrel{a}{\leftrightarrows} \\
\ddot{\dot{\theta}} \\
\text { }\end{array}$ & 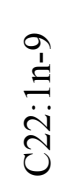 \\
\hline 1 & 2 & 3 & 4 & 5 & 6 & 7 & 8 & 9 & 10 & 11 & 12 & 13 \\
\hline $\begin{array}{l}\dot{\phi} \\
\dot{\phi}\end{array}$ & $\stackrel{\hat{\theta}}{0}$ & $\begin{array}{l}\stackrel{P}{0} \\
\dot{0}\end{array}$ & $\stackrel{\infty}{\infty}$ & $\stackrel{\infty}{\infty}$ & $\frac{a}{\dot{p}}$ & $\stackrel{0}{0}$ & $\begin{array}{l}\tilde{\infty} \\
0 \\
0\end{array}$ & $\begin{array}{l}\text { ñ } \\
\text { ? }\end{array}$ & $\begin{array}{l}\text { mै? } \\
\text { ?̦ }\end{array}$ & $\begin{array}{l}\text { r̂ } \\
\stackrel{1}{0}\end{array}$ & $\stackrel{\text { fo }}{\stackrel{0}{i}}$ & n़? \\
\hline
\end{tabular}




\begin{tabular}{|c|c|c|c|c|c|c|c|c|c|c|c|c|}
\hline 1 & 2 & 3 & 4 & 5 & 6 & 7 & 8 & 9 & 10 & 11 & 12 & 13 \\
\hline $\begin{array}{l}\dot{O} \\
\dot{0} \\
\end{array}$ & $\begin{array}{l}\bar{\sigma} \\
0\end{array}$ & $\begin{array}{l}0 \\
0 \\
0\end{array}$ & $\overrightarrow{0}$ & $\begin{array}{l}0 \\
0 \\
0\end{array}$ & $\begin{array}{l}\text { I̦ } \\
\stackrel{1}{1}\end{array}$ & $\frac{1}{0}$ & $\vec{i}$ & 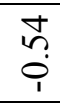 & $\begin{array}{l}\bar{n} \\
0 \\
\end{array}$ & $\begin{array}{l}\text { तै } \\
\text { ?̦ }\end{array}$ & $\begin{array}{l}\text { กิ } \\
\text { ị }\end{array}$ & $\frac{n}{0}$ \\
\hline$\stackrel{\stackrel{\leftrightarrow}{\vec{U}}}{\vec{u}}$ & $\ddot{\infty}$ & $\begin{array}{l}+ \\
\infty \\
0 \\
1\end{array}$ & 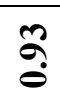 & $\stackrel{\circ}{\circ}$ & $\hat{n}$ & $=$ & $\begin{array}{l}2 \\
\infty \\
\dot{\rho}\end{array}$ & $\begin{array}{l}0 \\
\text { n? } \\
\text { ? }\end{array}$ & $\begin{array}{l}\text { సे } \\
\text { pे }\end{array}$ & $\stackrel{?}{\stackrel{f}{\varphi}}$ & $\begin{array}{l}\stackrel{+}{+} \\
\text { ị }\end{array}$ & $\begin{array}{l}\text { in } \\
\text { p̦ }\end{array}$ \\
\hline$\stackrel{\dot{m}}{\dot{m}}$ & $\begin{array}{l}0 \\
\text { ?̦ } \\
0\end{array}$ & $\begin{array}{l}\text { Na } \\
\text { in }\end{array}$ & ָे & $\stackrel{+}{+}$ & $\stackrel{m}{0}$ & ñn & 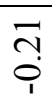 & $\stackrel{+}{\tilde{0}}$ & $\stackrel{\overbrace{}}{\text { ஸे }}$ & $\stackrel{\forall}{+}$ & $\begin{array}{l}n \\
n \\
i \\
i\end{array}$ & $\begin{array}{l}8 \\
0 \\
0\end{array}$ \\
\hline $\begin{array}{l} \\
\dot{\dot{U}} \\
\end{array}$ & g̊ & $\begin{array}{l}n \\
\infty \\
0 \\
0\end{array}$ & $\hat{o}$ & ڤ̊ & $\begin{array}{l}\text { N̦ } \\
\text { i }\end{array}$ & $\stackrel{8}{0}$ & $\begin{array}{l}2 \\
\dot{0} \\
\dot{1}\end{array}$ & 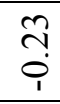 & $\begin{array}{l}n \\
0 \\
\end{array}$ & $\begin{array}{l}0 \\
\text { N̦ } \\
\text { in }\end{array}$ & $\begin{array}{l}n \\
n \\
i\end{array}$ & \begin{tabular}{l}
$n$ \\
\multirow{0}{0}{} \\
$i$
\end{tabular} \\
\hline $\begin{array}{l}\dot{\ddot{n}} \\
\dot{\ddot{U}}\end{array}$ & $\tilde{\dddot{0}}$ & $\stackrel{\substack{\infty \\
0}}{0}$ & $\stackrel{0}{\circ}$ & ָ̃ & $\begin{array}{l}+ \\
0 \\
0\end{array}$ & $\bar{\sigma}$ & Oे. & ñ & $\frac{2}{0}$ & $\begin{array}{l}\infty \\
\infty \\
0\end{array}$ & $\begin{array}{l}0 \\
0 \\
0\end{array}$ & $\stackrel{\infty}{\stackrel{\infty}{p}}$ \\
\hline $\begin{array}{l} \\
\dot{\theta} \\
\dot{U}\end{array}$ & $\stackrel{\hat{r}}{9}$ & $\begin{array}{l}m \\
? \\
?\end{array}$ & $\stackrel{R}{\stackrel{R}{0}}$ & $\stackrel{R}{\stackrel{9}{0}}$ & $\hat{n}$ & $\stackrel{n}{?}$ & $\stackrel{n}{\stackrel{n}{0}}$ & 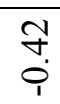 & $\underset{0}{+}$ & $\frac{N}{0}$ & $\begin{array}{l}n \\
n \\
0\end{array}$ & $\begin{array}{l}\text { o } \\
\text { : } \\
1\end{array}$ \\
\hline $\begin{array}{l}\stackrel{0}{\dot{U}} \\
\dot{U}\end{array}$ & $\sigma_{0}^{0}$ & $\stackrel{\tilde{n}}{0}$ & $\stackrel{?}{\stackrel{9}{1}}$ & $\begin{array}{l}8 \\
0 \\
0\end{array}$ & $\stackrel{\mathfrak{T}}{9}$ & $\begin{array}{l}\infty \\
\infty \\
0\end{array}$ & $\begin{array}{l}\text { D. } \\
0\end{array}$ & $\underset{0}{\stackrel{J}{0}}$ & $\begin{array}{l}\infty \\
\infty \\
0\end{array}$ & $\ddot{\infty}$ & $\begin{array}{l}\stackrel{+}{+} \\
\stackrel{p}{p}\end{array}$ & $\begin{array}{l}\text { ñ } \\
\text { in }\end{array}$ \\
\hline $\begin{array}{l}0 \\
\dot{0} \\
\dot{0}\end{array}$ & $\begin{array}{l}n \\
n \\
0 \\
1\end{array}$ & $\stackrel{\infty}{0}$ & $\frac{N}{0}$ & $\begin{array}{l}\text { Mo } \\
\dot{0}\end{array}$ & $\stackrel{a}{0}$ & $\underset{0}{*}$ & $\stackrel{m}{0}$ & $\frac{}{0}$ & $\stackrel{\circ}{n}$ & $\bar{n}$ & $\frac{\infty}{0}$ & $\begin{array}{l}\stackrel{0}{0} \\
0\end{array}$ \\
\hline $\begin{array}{l}\dot{\hat{\theta}} \\
\text { Uे }\end{array}$ & $\begin{array}{l}0 \\
? \\
0 \\
1\end{array}$ & $\stackrel{\infty}{\stackrel{\infty}{0}}$ & $\begin{array}{l}n \\
\infty \\
0 \\
1\end{array}$ & $\underset{+}{\stackrel{+}{\varphi}}$ & ते & 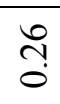 & 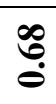 & $\stackrel{n}{n}$ & $\stackrel{n}{n}$ & กี & సे? & กิ \\
\hline 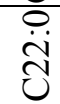 & $\begin{array}{l}\stackrel{0}{0} \\
\dot{p}\end{array}$ & $\stackrel{g}{0}$ & $\begin{array}{l}8 \\
\infty \\
0 \\
1\end{array}$ & $\underset{⿱ 亠 巾}{\stackrel{T}{i}}$ & 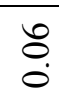 & $\stackrel{0}{0}$ & $\ddot{\theta}$ & $\stackrel{n}{o}$ & $\stackrel{\text { กิ }}{0}$ & $\underset{\circ}{\nabla}$ & $\stackrel{\mathfrak{T}}{\circ}$ & ָָ \\
\hline
\end{tabular}

Много значимых как прямых, так и обратных корреляций наблюдается между содержанием насыщенных и мононенасыщенных кислот (табл. 7). Наиболее тесные прямые корреляции наблюдаются между содержанием ЖК С12:0, C14:0 и C16:1n-7, C16:1n-5 ( $R$ варьирует от 0.86 до 0.97). Между короткоцепочными насыщенными ЖК и полиненасыщенными ЖК преобладают отрицательные корреляции (табл.8). Длинноцепочные насыщенные ЖК, напротив, имеют тенденцию симбатно возрастать при росте содержания полиненасыщенных ЖК.

Таблица 8. Матрица коэффициентов парной корреляции $R$ между $W(\%)$ насыщенных ЖК и полиненасыщенных ЖК в грудном молоке $(n=440, P=0.95)$

\begin{tabular}{|c|c|c|c|c|c|c|c|c|c|c|c|c|c|c|c|c|}
\hline ЖК & 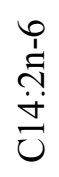 & 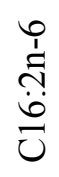 & $\begin{array}{l}0 \\
\stackrel{1}{n} \\
\stackrel{1}{0} \\
\dot{\infty} \\
ن\end{array}$ & $\begin{array}{l}0 \\
\stackrel{1}{1} \\
\stackrel{n}{\infty} \\
\ddot{\infty} \\
\dot{U}\end{array}$ & 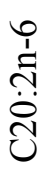 & 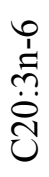 & 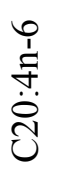 & 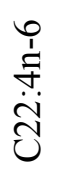 & 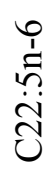 & $\begin{array}{l}\stackrel{m}{\dot{1}} \\
\stackrel{m}{\infty} \\
\stackrel{\infty}{U}\end{array}$ & 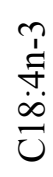 & $\begin{array}{l}\stackrel{m}{\dot{n}} \\
\stackrel{n}{0} \\
\stackrel{O}{U}\end{array}$ & 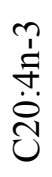 & 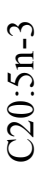 & 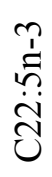 & 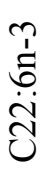 \\
\hline 1 & 2 & 3 & 4 & 5 & 6 & 7 & 8 & 9 & 10 & 11 & 12 & 13 & 14 & 15 & 16 & 17 \\
\hline $\begin{array}{l}\stackrel{0}{\dot{\infty}} \\
\dot{\phi}\end{array}$ & $\begin{array}{l}\stackrel{0}{1} \\
\stackrel{1}{i}\end{array}$ & $\begin{array}{l}0 \\
\text { n? } \\
\text { p. }\end{array}$ & ?़े? & $\begin{array}{l}\text { मे } \\
\dot{\varphi}\end{array}$ & $\frac{\infty}{\stackrel{0}{\varphi}}$ & $\begin{array}{l}n \\
\dot{p} \\
\dot{p}\end{array}$ & $\begin{array}{l}\text { + } \\
\stackrel{1}{1}\end{array}$ & $\stackrel{n}{0}$ & $\hat{0}$ & $\begin{array}{l}\text { ț } \\
\dot{9}\end{array}$ & $\stackrel{9}{0}$ & $\begin{array}{l}\infty \\
\stackrel{\leftrightarrow}{\varphi} \\
\stackrel{p}{1}\end{array}$ & 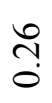 & $\stackrel{\infty}{n}$ & $\stackrel{0}{:}$ & $\vec{\rho}$ \\
\hline $\begin{array}{l}\stackrel{\leftrightarrow}{0} \\
\dot{0}\end{array}$ & \begin{tabular}{l}
\multirow{J}{*}{} \\
$\stackrel{1}{*}$
\end{tabular} & ñ & $\begin{array}{l}n \\
n \\
0\end{array}$ & $\begin{array}{l}N \\
\infty \\
\end{array}$ & $\begin{array}{l}\stackrel{8}{0} \\
\stackrel{0}{0}\end{array}$ & $\begin{array}{l}\infty \\
\stackrel{0}{0} \\
0\end{array}$ & $\stackrel{\sim}{\tilde{r}}$ & 仓̊ & $\stackrel{?}{\stackrel{0}{0}}$ & $\begin{array}{l}\stackrel{+}{+} \\
\stackrel{1}{0}\end{array}$ & $\stackrel{\overbrace{}}{\tilde{0}}$ & $\begin{array}{l}0 \\
\stackrel{0}{0} \\
\stackrel{1}{0}\end{array}$ & กี & $\begin{array}{l}\stackrel{J}{0} \\
\stackrel{0}{0}\end{array}$ & $\stackrel{n}{\stackrel{n}{8}}$ & $\stackrel{\overbrace{}}{\stackrel{\theta}{\theta}}$ \\
\hline$\underset{\stackrel{\circlearrowright}{U}}{\stackrel{O}{U}}$ & 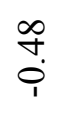 & $\begin{array}{l}\text { ñ } \\
0 \\
1\end{array}$ & 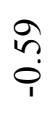 & $\begin{array}{l}n \\
\infty \\
0 \\
0\end{array}$ & $\frac{1}{0}$ & $\stackrel{8}{\circ}$ & 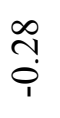 & $\frac{1}{0}$ & $\tilde{n}$ & $\begin{array}{l}\stackrel{R}{0} \\
\dot{p}\end{array}$ & $\begin{array}{l}8 \\
\end{array}$ & $\begin{array}{l}0 \\
\text { N̦ } \\
\text { p }\end{array}$ & $\begin{array}{l}\text { Oे. } \\
0\end{array}$ & $\stackrel{+}{m}$ & $\stackrel{?}{\circ}$ & 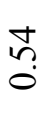 \\
\hline$\underset{\ddot{\theta}}{\stackrel{\oplus}{u}}$ & $\hat{n}$ & ?ִ & $\stackrel{n}{n}$ & $\frac{ \pm}{0}$ & $\frac{n}{9}$ & 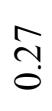 & $\begin{array}{l}n \\
\infty \\
0 \\
0\end{array}$ & $\begin{array}{l}\tilde{0} \\
\dot{0} \\
1\end{array}$ & $\begin{array}{l}\text { ñ } \\
\text { po }\end{array}$ & $\begin{array}{c}\hat{n} \\
\mathfrak{i}_{1}\end{array}$ & ণे & $\begin{array}{l}n \\
n \\
i\end{array}$ & $\frac{m}{0}$ & $\frac{N}{0}$ & $\overline{0}$ & o. \\
\hline
\end{tabular}




\begin{tabular}{|c|c|c|c|c|c|c|c|c|c|c|c|c|c|c|c|c|}
\hline 1 & 2 & 3 & 4 & 5 & 6 & 7 & 8 & 9 & 10 & 11 & 12 & 13 & 14 & 15 & 16 & 17 \\
\hline 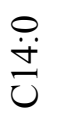 & 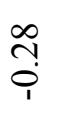 & ?ֶ? & $\begin{array}{l}n \\
\text { ñ } \\
\text { in }\end{array}$ & $\stackrel{0}{\stackrel{0}{i}}$ & $\begin{array}{l}\text { กิ } \\
\text { }\end{array}$ & $\begin{array}{l}\stackrel{\circ}{0} \\
\dot{0}\end{array}$ & $\begin{array}{l}n \\
\stackrel{n}{p} \\
\stackrel{1}{1}\end{array}$ & $\stackrel{n}{\circ}$ & $\stackrel{n}{\circ}$ & $\begin{array}{l}\text { Do } \\
0 \\
0\end{array}$ & $\frac{m}{\dot{9}}$ & $\stackrel{\text { f̣ }}{\stackrel{\varphi}{i}}$ & $\begin{array}{l}0 \\
\hat{\varphi}\end{array}$ & $\stackrel{n}{\tilde{n}}$ & $\stackrel{\text { I }}{\circ}$ & 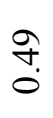 \\
\hline $\begin{array}{l}\stackrel{\leftrightarrow}{\ddot{n}} \\
\end{array}$ & $\stackrel{\leftrightarrow}{\hat{\theta}}$ & $\bar{\sigma}$ & $\underset{1}{\stackrel{1}{0}}$ & ñ? & $\begin{array}{l}n \\
n \\
0\end{array}$ & $\frac{9}{0}$ & $\stackrel{\Re}{\stackrel{0}{0}}$ & $\begin{array}{l}\vec{j} . \\
\dot{i}\end{array}$ & $\begin{array}{l}\bar{n} \\
0 \\
1\end{array}$ & $\begin{array}{l}\overrightarrow{+} \\
\dot{P}\end{array}$ & 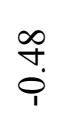 & $\underset{⿱}{\stackrel{+}{0}}$ & $\begin{array}{l}\text { N̦ } \\
\stackrel{1}{1}\end{array}$ & $\stackrel{8}{8}$ & $\stackrel{-}{0}$ & ก̋ \\
\hline $\begin{array}{l}\stackrel{0}{\dot{b}} \\
\dot{U}\end{array}$ & ָ̃ & $\begin{array}{l}0 \\
0 \\
\dot{\varphi}\end{array}$ & $\frac{\infty}{\stackrel{0}{0}}$ & $\begin{array}{l}0 \\
\text { Ṇ} \\
\stackrel{1}{1}\end{array}$ & $\begin{array}{l}n \\
n \\
0\end{array}$ & $\overrightarrow{\overrightarrow{0}}$ & $\begin{array}{l}0 \\
\stackrel{0}{0} \\
\stackrel{1}{1}\end{array}$ & $\stackrel{\sim}{0}$ & $\begin{array}{l}\vec{ก} \\
\stackrel{\varphi}{1}\end{array}$ & $\begin{array}{l}\text { Co } \\
0\end{array}$ & $\begin{array}{l}\text { Dे. } \\
\stackrel{0}{0}\end{array}$ & $\underset{i}{\stackrel{J}{*}}$ & $\stackrel{\Xi}{0}$ & กै? & $\overrightarrow{\widetilde{o}}$ & तָ \\
\hline 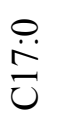 & $\begin{array}{l}\stackrel{0}{0} \\
\stackrel{0}{0}\end{array}$ & $\stackrel{\Delta}{0}$ & $\stackrel{\infty}{\stackrel{0}{0}}$ & ?n & $\begin{array}{l}\stackrel{0}{0} \\
\dot{0}\end{array}$ & ָे & ले & $\begin{array}{l}\infty \\
\dddot{n} \\
\stackrel{1}{1}\end{array}$ & त̂? & ָे & 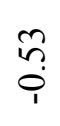 & 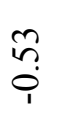 & $\begin{array}{l}0 \\
\text { ְn } \\
i\end{array}$ & $\begin{array}{l} \pm \\
0 \\
\end{array}$ & $\begin{array}{l}\text { oे } \\
\text { i }\end{array}$ & $\begin{array}{l}\text { N̦ } \\
\text { ị }\end{array}$ \\
\hline $\begin{array}{l}\stackrel{0}{\dot{\infty}} \\
\end{array}$ & $\stackrel{R}{\stackrel{R}{\theta}}$ & $\stackrel{5}{6}$ & $\stackrel{\substack{n \\
0}}{0}$ & $\stackrel{\infty}{\infty}$ & $\stackrel{0}{\stackrel{0}{0}}$ & $\begin{array}{l}\infty \\
\stackrel{0}{0} \\
\stackrel{1}{1}\end{array}$ & Oे. & 立 & $\begin{array}{l}\tilde{6} \\
\dot{0}\end{array}$ & $\stackrel{n}{\stackrel{n}{0}}$ & $\begin{array}{l}0 \\
0 \\
0\end{array}$ & $\stackrel{\infty}{\circ}$ & ô. & $\begin{array}{l}0 \\
\stackrel{0}{0}\end{array}$ & $\overrightarrow{\tilde{̣}}$ & 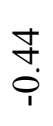 \\
\hline $\begin{array}{l}\stackrel{\leftrightarrow}{\dot{\Theta}} \\
\text { Uे }\end{array}$ & $\tilde{n}$ & $\begin{array}{l}\stackrel{8}{0} \\
\stackrel{0}{0}\end{array}$ & $\stackrel{n}{n}$ & $\stackrel{\frac{1}{2}}{\stackrel{\theta}{6}}$ & సે & $\frac{1}{0}$ & $\frac{0}{0}$ & 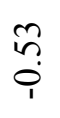 & $\stackrel{n}{m}$ & $\stackrel{r}{0}$ & 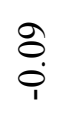 & ஸి & $\frac{9}{0}$ & $\underset{\dot{i}}{\stackrel{ \pm}{i}}$ & $\frac{\sim}{\stackrel{1}{1}}$ & 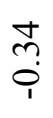 \\
\hline $\begin{array}{l}\stackrel{\leftrightarrow}{ \pm} \\
\stackrel{\bigcup}{U}\end{array}$ & $\overrightarrow{\tilde{o}}$ & $\stackrel{n}{n}$ & $\stackrel{n}{n}$ & $\stackrel{\infty}{n}$ & $\tilde{\overbrace{}}$ & $\begin{array}{l}0 \\
0 \\
0\end{array}$ & त̂ & $\begin{array}{l}n \\
n \\
i \\
i\end{array}$ & 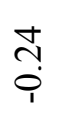 & $\begin{array}{l}\stackrel{0}{\circ} \\
\stackrel{0}{0}\end{array}$ & 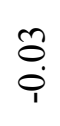 & 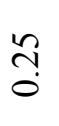 & $\stackrel{+}{0}$ & $\frac{1}{\dot{0}}$ & $\begin{array}{l}\text { ণ़ } \\
\text { }\end{array}$ & n़? \\
\hline $\begin{array}{l}\stackrel{\leftrightarrow}{ \pm} \\
\text { Ud }\end{array}$ & ?ొ & $\sqrt[n]{n}$ & $\overrightarrow{+}$. & ๗ે? & $\stackrel{n}{n}$ & $\stackrel{\infty}{\infty}$ & $\stackrel{m}{\overrightarrow{0}}$ & $\vec{i}$ & $\stackrel{+}{n}$ & $\begin{array}{l}\infty \\
\stackrel{0}{0} \\
\stackrel{1}{1}\end{array}$ & 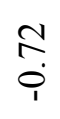 & 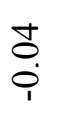 & $\frac{ \pm}{\stackrel{0}{0}}$ & $\vec{m}$ & oे. & n़? \\
\hline
\end{tabular}

Хорошие корреляции имеют место между содержанием мононенасыщенных кислот (табл. 9), так содержание C14:1n-5 тесно коррелирует с содержанием C16:1n7 и C16:1n-5 (R>0.95), а доля C16:1n-7 прямо пропорциональна доли C16:1n-5 $(R=0.98)$, тесной парой являются ЖК С20:1n-9 и С22:1n-9 $(R=0.97)$.

Таблица 9. Матрица коэффициентов парной корреляции $\mathrm{R}$ между $W(\%)$ полиненасыщенных ЖК в грудном молоке $(n=440, P=0.95)$

\begin{tabular}{|c|c|c|c|c|c|c|c|c|c|c|c|c|}
\hline ЖК & $\begin{array}{l}\stackrel{\mathfrak{I}}{\Xi} \\
\stackrel{\dot{\Xi}}{\Xi} \\
\end{array}$ & $\begin{array}{l}\stackrel{a}{\Xi} \\
\ddot{\theta} \\
\dot{U}\end{array}$ & $\begin{array}{l}\hat{I} \\
\ddot{\theta} \\
\vec{U}\end{array}$ & 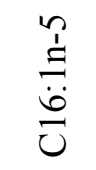 & $\begin{array}{l}\stackrel{\mathscr{I}}{\Xi} \\
\ddot{U}\end{array}$ & $\frac{\overparen{I}}{\stackrel{\Xi}{\Xi}}$ & 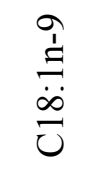 & $\begin{array}{l}\widehat{\Xi} \\
\stackrel{\infty}{\infty} \\
\vec{U}\end{array}$ & $\begin{array}{c}\stackrel{n}{\Xi} \\
\stackrel{\infty}{\infty} \\
\vec{U}\end{array}$ & 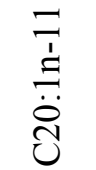 & $\begin{array}{l}\stackrel{a}{\Xi} \\
\stackrel{\dot{\theta}}{0} \\
\dot{U}\end{array}$ & $\begin{array}{l}\stackrel{a}{\stackrel{1}{二}} \\
\underset{\sim}{\tilde{U}}\end{array}$ \\
\hline 1 & 2 & 3 & & 4 & 5 & 6 & 7 & 8 & 9 & 10 & 11 & 12 \\
\hline C14:1n-5 & 1 & -0.77 & 0.97 & 0.96 & 0.15 & 0.36 & -0.67 & -0.09 & 0.16 & -0.14 & -0.75 & -0.61 \\
\hline C16:1n-9 & & 1 & -0.84 & -0.77 & 0.21 & 0.00 & 0.64 & 0.02 & 0.11 & 0.25 & 0.48 & 0.41 \\
\hline C16:1n-7 & & & 1 & 0.98 & -0.07 & 0.19 & -0.80 & -0.13 & 0.01 & -0.25 & -0.67 & -0.53 \\
\hline $\mathrm{C} 16: 1 \mathrm{n}-5$ & & & & 1 & 0.02 & 0.35 & -0.82 & -0.02 & 0.16 & -0.07 & -0.78 & -0.67 \\
\hline $\mathrm{C} 16: 1 \mathrm{n}-3$ & & & & & 1 & 0.78 & 0.35 & 0.22 & 0.75 & 0.62 & -0.47 & -0.50 \\
\hline $\mathrm{C} 17: 1 \mathrm{n}-7$ & & & & & & 1 & -0.04 & 0.38 & 0.86 & 0.68 & -0.66 & -0.72 \\
\hline C18:1n-9 & & & & & & & 1 & 0.13 & 0.13 & 0.10 & 0.53 & 0.45 \\
\hline C18:1n-7 & & & & & & & & 1 & 0.61 & 0.53 & -0.42 & -0.53 \\
\hline C18:1n-5 & & & & & & & & & 1 & 0.66 & -0.59 & -0.62 \\
\hline
\end{tabular}




\begin{tabular}{|c|c|c|c|c|c|c|c|c|c|c|c|c|}
\hline 1 & 2 & 3 & & 4 & 5 & 6 & 7 & 8 & 9 & 10 & 11 & 12 \\
\hline C20:1n-11 & & & & & & & & & & 1 & -0.49 & -0.65 \\
\hline C20:1n-9 & & & & & & & & & & & 1 & $\mathbf{0 . 9 7}$ \\
\hline C22:1n-9 & & & & & & & & & & & 1 \\
\hline
\end{tabular}

Таблица 10. Матрица коэффициентов парной корреляции $R$ между $W(\%)$ моно- и полиненасыщенных ЖК в грудном молоке $(n=440, P=0.95)$

\begin{tabular}{|c|c|c|c|c|c|c|c|c|c|c|}
\hline ЖК & 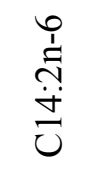 & 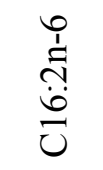 & 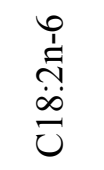 & $\begin{array}{l}0 \\
\stackrel{1}{n} \\
\stackrel{n}{\infty} \\
ٍ \\
己\end{array}$ & 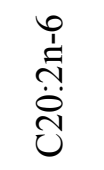 & $\begin{array}{l}0 \\
\stackrel{1}{f} \\
\dot{\overbrace{}} \\
\dot{O}\end{array}$ & 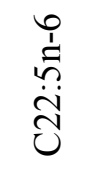 & 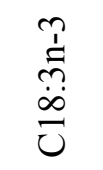 & $\begin{array}{c}\stackrel{n}{\dot{s}} \\
\stackrel{+}{\infty} \\
\overrightarrow{0}\end{array}$ & 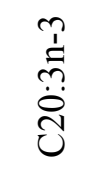 \\
\hline C14: & .00 & .11 & 0.79 & 0.47 & 0.55 & -0.65 & 0.09 & -0.90 & -0.29 & -0.66 \\
\hline C16:1n-9 & 0.36 & 0.36 & 0.57 & 0.73 & 0.33 & 0.45 & -0.27 & 0.68 & 0.01 & 0.47 \\
\hline C16:1n-7 & -0.19 & -0.26 & -0.69 & -0.63 & -0.37 & -0.51 & 0.30 & -0.88 & -0.23 & -0.55 \\
\hline $\mathrm{C} 16: 1 \mathrm{n}-5$ & -0.03 & $\begin{array}{l}-0.08 \\
\end{array}$ & -0.63 & -0.52 & -0.34 & $\begin{array}{l}-0.59 \\
\end{array}$ & 0.30 & -0.94 & -0.36 & -0.65 \\
\hline C16:1n-3 & 0.88 & 0.77 & -0.28 & 0.55 & -0.62 & -0.57 & -0.79 & -0.2 & -0.21 & -0.59 \\
\hline C17:1n-7 & .85 & 0.85 & -0.24 & 0.45 & -0.36 & -0.69 & -0.35 & -0.49 & -0.65 & -0.68 \\
\hline C18:1n-9 & 0.25 & 0.21 & 0.19 & 0.72 & -0.19 & 0.21 & -0.71 & 0.76 & 0.17 & 0.33 \\
\hline C18:1n-7 & 0.38 & 0.52 & 0.38 & 0.49 & 0.06 & -0.15 & -0.09 & -0.20 & -0.56 & -0.51 \\
\hline C18:1n-5 & 0.73 & 0.81 & 0.01 & 0.57 & -0.31 & -0.35 & -0.31 & -0.41 & -0.69 & -0.66 \\
\hline C20:1n-11 & 0.80 & 0.86 & 0.28 & 0.40 & -0.04 & -0.39 & -0.29 & -0.14 & -0.20 & -0.56 \\
\hline C20:1n-9 & -0.46 & -0.43 & 0.38 & 0.10 & 0.44 & 0.70 & 0.06 & 0.91 & 0.44 & 0.96 \\
\hline C22:1n-9 & -0.56 & -0.56 & 0.26 & 0.00 & 0.35 & 0.73 & 0.10 & 0.81 & 0.44 & 0.96 \\
\hline
\end{tabular}

Таблица 11. Матрица коэффициентов парной корреляции $R$ между $W(\%)$ полиненасыщенных ЖК в грудном молоке $(n=440, P=0.95)$

\begin{tabular}{|c|c|c|c|c|c|c|c|c|c|c|c|c|c|c|c|c|}
\hline ЖК & 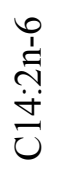 & $\begin{array}{l}\stackrel{0}{\perp} \\
\stackrel{\Lambda}{1} \\
\stackrel{0}{U}\end{array}$ & 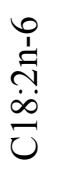 & 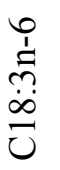 & 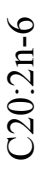 & 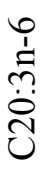 & 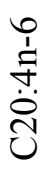 & 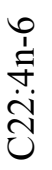 & 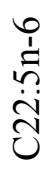 & $\begin{array}{l}\stackrel{\mathscr{1}}{\tilde{n}} \\
\stackrel{\infty}{\infty} \\
\stackrel{0}{0}\end{array}$ & 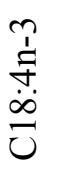 & 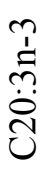 & 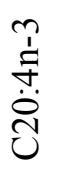 & 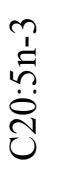 & $\begin{array}{l}\stackrel{\tilde{n}}{\tilde{n}} \\
\stackrel{\tilde{U}}{U}\end{array}$ & 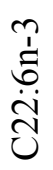 \\
\hline 1 & 2 & 3 & 4 & 5 & 6 & 7 & 8 & 9 & 10 & 11 & 12 & 13 & 14 & 15 & 16 & 17 \\
\hline $\mathrm{C} 14: 2 \mathrm{n}-6$ & - & 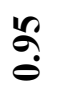 & $\stackrel{\overline{0}}{0}$ & $\begin{array}{l}\stackrel{\leftrightarrow}{0} \\
\stackrel{\leftrightarrow}{0}\end{array}$ & 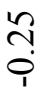 & $\frac{0}{0}$ & 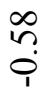 & $\begin{array}{l}\stackrel{+}{n} \\
\stackrel{i}{1}\end{array}$ & $\begin{array}{l}8 \\
\dot{0} \\
\dot{0}\end{array}$ & $\begin{array}{l}0 \\
\frac{1}{1}\end{array}$ & $\begin{array}{l}0 \\
\text { ñ? } \\
\text { in }\end{array}$ & $\begin{array}{l}n \\
n \\
i \\
1\end{array}$ & $\frac{1}{0}$ & $\begin{array}{l}\text { ô } \\
\hat{\varphi}\end{array}$ & $\frac{\pi}{0}$ & 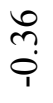 \\
\hline C16:2n-6 & & - & กิ & $\begin{array}{l}\hat{\sigma} \\
\dot{0}\end{array}$ & $\begin{array}{l}\stackrel{2}{0} \\
\stackrel{1}{0}\end{array}$ & ?̊? & $\stackrel{\text { fo }}{i}$ & \begin{tabular}{l}
0 \\
\multirow{1}{*}{} \\
i.
\end{tabular} & 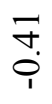 & $\frac{ \pm}{\dot{0}}$ & $\stackrel{\infty}{+}$ & $\stackrel{\text { جे }}{i}$ & $\begin{array}{l}\hat{N} \\
\stackrel{1}{1}\end{array}$ & $\frac{\stackrel{1}{0}}{i}$ & $\begin{array}{l}\text { กิ } \\
\stackrel{1}{1}\end{array}$ & 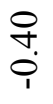 \\
\hline C18:2n-6 & & & - & กै? & $\ddot{\infty}$ & $\tilde{n}$ & $\begin{array}{l}\text { ț } \\
\stackrel{0}{0}\end{array}$ & $\frac{ \pm}{\dot{\varphi}}$ & m? & $\stackrel{\infty}{+}$ & $\begin{array}{l}\text { ô } \\
\text { ̣. }\end{array}$ & ભે & $\begin{array}{l}\text { ָ̣ } \\
\text { }\end{array}$ & $\begin{array}{l}n \\
n \\
0 \\
1\end{array}$ & $\frac{\overline{0}}{\dot{\varphi}}$ & $\begin{array}{l}\text { đ̦ } \\
\stackrel{1}{1}\end{array}$ \\
\hline C18:3n-6 & & & & - & $\begin{array}{l}\text { ro } \\
\stackrel{i}{1}\end{array}$ & ণે & $\stackrel{8}{\circ}$ & $\overrightarrow{\widetilde{N}}$ & $\begin{array}{l}0 \\
n \\
?\end{array}$ & ?ొ? & $\begin{array}{l}\text { fo } \\
\stackrel{f}{i}\end{array}$ & $\stackrel{8}{\circ}$ & 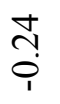 & $\begin{array}{l}0 \\
n \\
? \\
?\end{array}$ & $\begin{array}{l}\hat{b} \\
\stackrel{i}{i}\end{array}$ & $\stackrel{\infty}{\infty}$ \\
\hline$C 20: 2 n-6$ & & & & & - & $\begin{array}{l}\stackrel{\infty}{\circ} \\
\stackrel{0}{0}\end{array}$ & $\tilde{n}$ & त̂ & 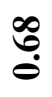 & ñ? & $\begin{array}{l}\text { I } \\
\dot{0}\end{array}$ & $\begin{array}{l}\stackrel{0}{n} \\
? \\
0\end{array}$ & $\begin{array}{l}n \\
0 \\
0\end{array}$ & 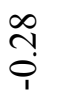 & $\begin{array}{l}\infty \\
\stackrel{0}{0} \\
0\end{array}$ & $\stackrel{8}{8}$ \\
\hline C20:3n-6 & & & & & & - & $\overrightarrow{0}$ & $\begin{array}{l}\tilde{n} \\
\text { ñ } \\
\text { in }\end{array}$ & $\begin{array}{l}\stackrel{2}{n} \\
\text { ñ }\end{array}$ & 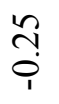 & $\begin{array}{l}n \\
0 \\
i\end{array}$ & 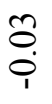 & $\begin{array}{l}0 \\
\text { n़ } \\
\text { ì }\end{array}$ & $\stackrel{\text { fo }}{\stackrel{\text { P}}{1}}$ & $\frac{\infty}{\dot{1}}$ & \begin{tabular}{l}
$\infty$ \\
\multirow{i}{i}{} \\
$\stackrel{1}{1}$
\end{tabular} \\
\hline
\end{tabular}




\begin{tabular}{|c|c|c|c|c|c|c|c|c|c|c|c|c|c|c|c|c|}
\hline 1 & 2 & 3 & 4 & 5 & 6 & 7 & 8 & 9 & 10 & 11 & 12 & 13 & 14 & 15 & 16 & 17 \\
\hline$C 20: 4 n-6$ & & & & & & & - & $\stackrel{?}{\stackrel{f}{o}}$ & $\stackrel{\mathscr{\vartheta}}{\circ}$ & $\tilde{n}$ & $\stackrel{\overbrace{}}{0}$ & $\stackrel{\mathfrak{r}}{\stackrel{\theta}{\theta}}$ & ô. & $\begin{array}{l}0 \\
\text { ñ } \\
\text { p’ }\end{array}$ & $\frac{1}{\dot{p}}$ & $\begin{array}{l}n \\
0 \\
0\end{array}$ \\
\hline C18:3n-3 & & & & & & & & & & - & $\begin{array}{l}0 \\
\stackrel{0}{0}\end{array}$ & $\stackrel{\infty}{\oplus}$ & $\stackrel{\infty}{\stackrel{\infty}{0}}$ & $\frac{ \pm}{\dot{P}}$ & $\begin{array}{l}\infty \\
0 \\
0\end{array}$ & $\frac{ \pm}{\dot{0}}$ \\
\hline C18:4n-3 & & & & & & & & & & & - & $\begin{array}{l}\infty \\
\text { n? } \\
0\end{array}$ & $\begin{array}{l}\stackrel{8}{0} \\
\dot{0}\end{array}$ & $\stackrel{0}{n}$ & $\ddot{n}$ & $\begin{array}{l}8 \\
\stackrel{8}{0}\end{array}$ \\
\hline C20:4n-3 & & & & & & & & & & & & & - & $\stackrel{\mathfrak{N}}{\dot{\theta}}$ & $\stackrel{R}{\stackrel{0}{0}}$ & $\stackrel{\mathscr{b}}{0}$ \\
\hline$C 20: 5 n-3$ & & & & & & & & & & & & & & - & $\bar{g}$ & $\bar{g}$ \\
\hline$C 22: 5 n-3$ & & & & & & & & & & & & & & & - & 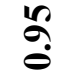 \\
\hline $\mathrm{C} 22: 6 \mathrm{n}-3$ & & & & & & & & & & & & & & & & -1 \\
\hline
\end{tabular}

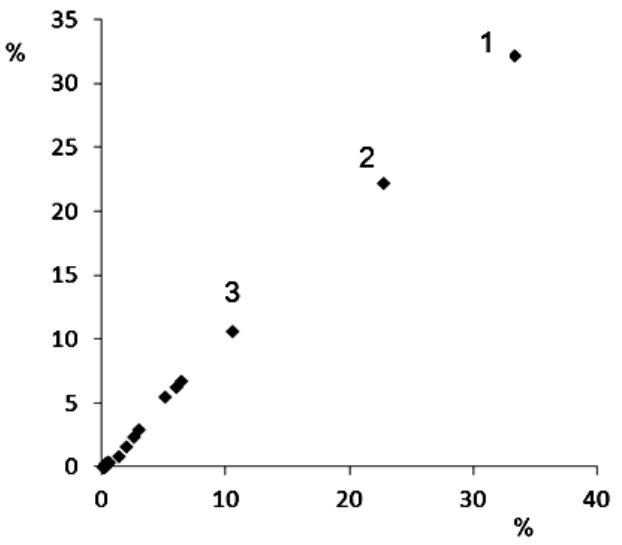

Рис. 1. Корреляция между общим составом ЖК грудного молока в Англии (ось X) и Австралии (ось Y): 1 - C18:1n-9; 2 - C16:0; 3 - C18:2n-6

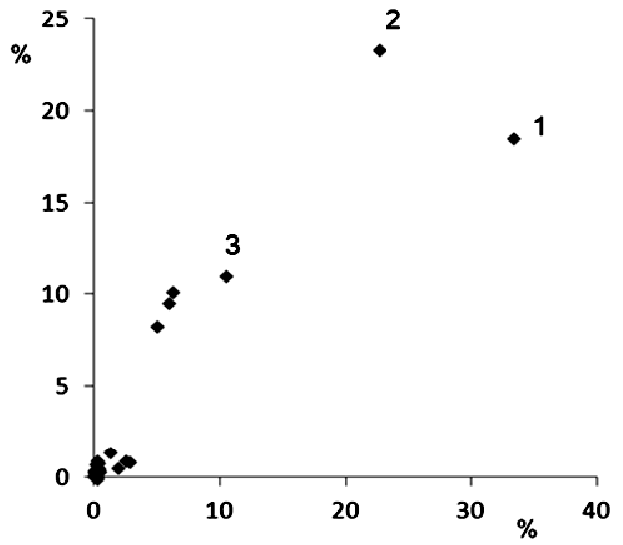

Рис. 2. Корреляция между общим составом ЖК грудного молока в Англии (ось X) и Нигерии (ось Y): 1 - C18:1n-9; 2 - C16:0; 3 - C18:2n-6

Разнонаправленные тренды характеризуют корреляции между моно- и полиненасыщенными ЖК. Так, содержание C18:3n-3 падает при росте содержания C14:1n-5, но растет при росте доли C14:1n-5 и C22:1n-9, содержание последних с высокой степенью корреляции соотносится с содержанием C18:4n-3 и C20:3n-3 $(R=0.96)$.

Что касается полиненасыщенных ЖК, наиболее часто их содержание изменяется симбатно, если растет содержание одной кислоты, возрастает содержание и целого ряда других ЖК (табл. 11), причем в 4 случаях коэффициенты $R>0.90$.

Таким образом, доли одних ЖК грудного молока в зависимости от региона, рациона питания женщин симбатно растут с долями других или понижаются при росте сравниваемых ЖК в соответствии с найденными корреляциями. 


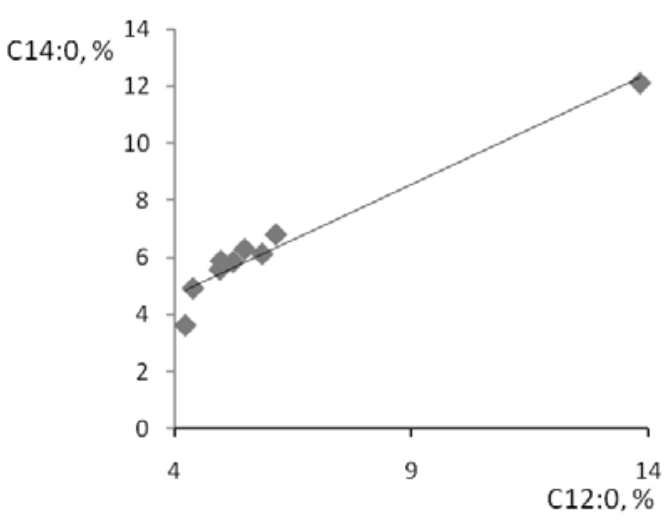

Рис. 3. Корреляция между содержанием в грудном молоке миристиновой и лауриновой кислот по данным [6]

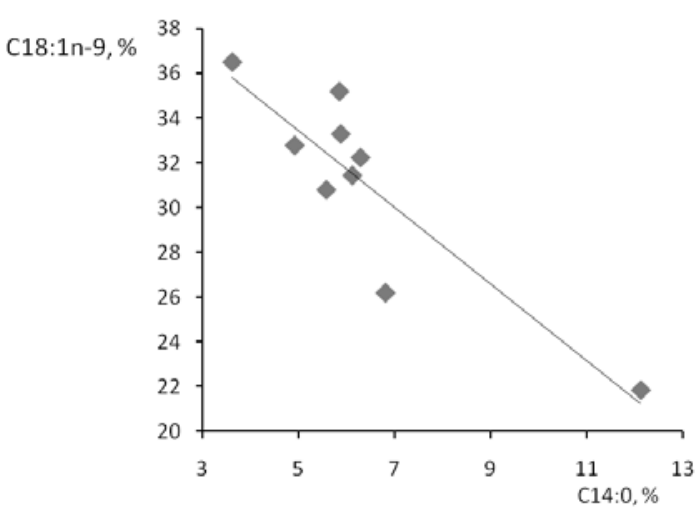

Рис. 4. Корреляция между содержанием в грудном молоке олеиновой и миристиновой кислот

Данные по грудному молоку в [6] статистически достоверны, не вызывает сомнений описанная в этом исследовании методика выполнения эксперимента. Данные [7-17] по основным ЖК согласуются с данными [6], но содержание минорных кислот и их идентификация менее достоверны, поэтому они использованы главным образом для сравнения суммарного состава (табл. 4).

На рис. 3,4 приведены примеры прямой и обратной корреляции между содержанием ЖК в грудном молоке. В работе [18] показано, что соотношение между ЖК в грудном женском молоке и молоке животных (например, коровьем молоке) может существенно различаться. Это обстоятельство может служить признаком натуральности грудного молока и применимо при выявлении его фальсификации. Так, для коровьего молока соотношение $\mathrm{C} 12: 0 / \mathrm{C} 10: 0$ близко к 1, а для грудного молока близко к 3. В коровьем молочном жире соотношение C14:0/C12:0 варьирует от 3 до 4, а в грудном молоке оно близко к 1. Можно выделить несколько таких характерных соотношений, позволяющих уверенно подтвердить натуральность женского молока или обнаружить фальсификат.

\section{Заключение}

Статистический анализ массива данных по жирно-кислотному составу зрелого грудного молока женщин из разных стран и регионов показал наличие значимых природных корреляций между содержанием некоторых насыщенных, моно- и полиненасыщенных высших жирных кислот. Выявленная фенотипическая изменчивость в составе ЖК натурального женского молока может быть использована для дальнейших биологических, биохимических и диетологических исследований. Наблюдаемые корреляции полезны при идентификации происхождения молока, при выявлении фальсифицированного женского молока, в оптимизации состава искусственных молочных смесей и адаптации их состава к особенностям региональной диеты кормящих женщин.

\section{Список литературы}

1. Лукоянова О.Л. // Вопросы современной педиатрии. 2012. Т.11. № 4. С. 111-115.

2. Рудаков О.Б., Рудакова Л.В. // Переработка молока. 2017. № 1. С. 40-42.
3. Рудаков О.Б., Пономарев А.Н., Полянский К.К., Любарь А.В. Жиры. Химический состав и экспертиза качества. М. Дели Принт. 2005. 312 c. 
4. Рудаков О.Б., Полянский К.К. Рудакова Л.В. // Переработка молока. 2018. № 2. С. 54-56.

5. Рудаков О.Б., Полянский К.К. // Переработка молока. 2018. № 4. С. 50-52.

6. Yuhas R., Pramuk K., Lien E.L. // Lipids. 2006. Vol. 41. No 9. pp. 851-858. DOI: 10.1007/s11745-006-5040-7

7. Zou X., Jin· Q., Guo Z., Xu X. et al. // J. Am. Oil Chem. Soc. 2016. Vol. 93. No 6. pp. 781-792. DOI 10.1007/s11746-016-2816-7.

8. Jackson K.H., Polreis J., Sanborn L., Chaima D. et al. // International Humanfeeding Journal. 2016. Vol. 11. No 1. DOI 10.1186/s13006-016-0060-2

9. Haddad I., Mozzon M., Frega N.G. // Eur. Food Res. Technol. 2012 Vol. 235. No 2. pp. 325-332. DOI 10.1007/s00217-012-1759-y

10.Nasser R., A.M. Stephen, Y.K. Goh, M. T. Clandinin // International Humanfeeding Journal. 2010. Vol. 5. No 3. https://doi.org/10.1186/1746-4358-5-3

11.Chen Z.Y., Kwan K.Y., Tong K.K., Ratnayake W.M.N et al. // Lipids. 1997.Vol. 32. No

\section{References}

1. Lukoyanova O.L., Voprosy sovremennoy pediatrii, 2012, Vol. 11, No 4, pp. 111-115 [in Russian].

2. Rudakov O.B., Rudakova L.V., Pererabotka moloka, 2017, No 1, pp. 40-42. [in Russian].

3. Rudakov O.B., Ponomarev A.N., Polyanskiy K.K., Lyubar' A.V., Zhiry. Khimicheskiy sostav i ekspertiza kachestva, M., Deli Print, 2005, 312 p. [in Russian].

4. Rudakov O.B., Polyanskiy K.K. Rudakova L.V., Pererabotka moloka, 2018, No 2, pp. 54-56. [in Russian].

5. Rudakov O.B., Polyanskiy K.K., Pererabotka moloka, 2018, No 4, pp. 50-52. [in Russian].

6. Yuhas R., Pramuk K., Lien E.L., Lipids, 2006, Vol. 41, No 9, pp. 851-858. DOI: 10.1007/s11745-006-5040-7

7. Zou X., Jin· Q., Guo Z., Xu X. et al., J. Am. Oil Chem. Soc., 2016, Vol. 93, No 6, pp. 781-792. DOI 10.1007/s11746-016-2816-7.

8. Jackson K.H., Polreis J., Sanborn L., Chaima D. et al., International Humanfeeding Journal, 2016, Vol. 11, No 1, DOI 10.1186/s13006-016-0060-2
10. pp. 1061-1067._DOI: 10.1007/s11745-997$0137-6$

12.Harzer G., Haug M., Bindels J.G. // Zeitschrift für Ernährungswissenschaft. 1986. Vol. 25. No 2. pp. 77-90. DOI: 10.1007/BF02020737.

13.Zou X., Huang J., Jin Q., Guo Z. et al. // J. Am. Oil Chem. Soc. 2014. Vol. 91. No 3. pp. 481-495. DOI 10.1007/s11746-013-2383-0

14.Haddad I., Mozzon M., Strabbioli R., Frega N.G. // Dairy Sci. \& Technol. 2012. Vol. 92. No 1. pp. 37-56. DOI 10.1007/s13594-011-0042-5

15.Samur G., Topcu A., Turan S. // Lipids. 2009. Vol. 44. No 5. pp. 405-413. DOI 10.1007/s11745-009-3293-7

16.Jensen R.G. // Lipids. 1999. Vol. 34. No 12. pp. 1243-1271._DOI: $10.1007 / \mathrm{s} 11745-999-$ 0477-2

17. Koletzko B., Thiel I., Abiodun P.O. // Zeitschrift für Ernährungswissenschaft. 1991. Vol. 30. No 4. pp. 289-297. DOI 10.1007/BF01651958

18.Рудаков О.Б., Рудакова Л.В., Букша М.С. // Переработка молока. 2018. № 9. С. 46-48.

9. Haddad I., Mozzon M., Frega N.G., Eur. Food Res. Technol., 2012, Vol. 235, No 2, pp. 325-332. DOI 10.1007/s00217-012-1759-y

10. Nasser R., Stephen A.M., Goh Y.K., Clandinin M.T., International Humanfeeding Journal, 2010, Vol. 5, No 3, https://doi.org/10.1186/1746-4358-5-3

11. Chen Z.Y., Kwan K.Y., Tong K.K., Ratnayake W.M.N et al., Lipids, 1997, Vol. 32, No 10, pp. 1061-1067._DOI: 10.1007/s11745-997$0137-6$

12. Harzer G., Haug M., Bindels J.G., Zeitschrift für Ernährungswissenschaft, 1986, Vol. 25, No 2, pp. 77-90. DOI: 10.1007/BF02020737.

13. Zou X., Huang J., Jin Q., Guo Z. et al., J. Am. Oil Chem. Soc., 2014, Vol. 91, No 3, pp. 481-495. DOI 10.1007/s11746-013-2383-0

14. Haddad I., Mozzon M., Strabbioli R., Frega N.G., Dairy Sci. \& Technol., 2012, Vol. 92, No 1, pp. 37-56. DOI 10.1007/s13594-0110042-5

15. Samur G., Topcu A., Turan S., Lipids, 2009, Vol. 44, No 5, pp. 405-413. DOI $10.1007 / \mathrm{s} 11745-009-3293-7$ 
16. Jensen R.G., Lipids, 1999, Vol. 34, No 30, No 4, pp. 289-297. DOI 12, pp. 1243-1271. DOI: 10.1007/s11745-999- $\underline{10.1007 / \mathrm{BF} 01651958}$ $0477-2$

17. Koletzko B., Thiel I., Abiodun P.O., Zeitschrift für Ernährungswissenschaft, 1991, Vol.

18. Rudakov O.B., Rudakova L.V., Buksha M.S., Pererabotka moloka, 2018, No 9, pp. 4648 [in Russian].

Рудаков Олег Борисович - д.Х.Н., зав. кафедрой химии и химической технологии материалов Воронежского государственного технического университета, Воронеж

Рудакова Людмила Васильевна - д.Х.н., зав. кафедрой фармацевтической химии и фармацевтической технологии Воронежского государственного медицинского университета, Воронеж

Букша Максим Сергеевич - студент Воронежского государственного медицинского университета, Воронеж

Rudakov Oleg B. - Dr. Sci (Chemistry), head of Department of chemistry and chemical technology of materials of Voronezh state technical University, Voronezh. E-mail: robi57@mail.ru

Rudakova Lyudmila V. - Dr. Sci (Chemistry), head of Department of pharmaceutical chemistry and pharmaceutical technology of Voronezh state medical University, Voronezh. E-mail: vodoley65@mail.ru

Buksha Maksim S. - Student of Voronezh state medical University, Voronezh. E-mail: snbuk@bk.ru 